\title{
Compensatory adrenal growth in relation to stress of surgery and estradiol in adult male rats
}

\author{
Nicholas Bikas, Joan Gribisi, Joan Messari and Anastasia Sfikakis
}

Department of Experimental Pharmacology and Department of Pathology, Athens University School of Medicine 11528 Athens, Greece

\begin{abstract}
ACTH infusion at the time of unilateral adrenalectomy inhibits the early rapid compensatory growth (CAG) in the remaining adrenal. We examined the hypothesis that different duration of surgery and/or the enhanced response to the stress of surgery, induced by estradiol treatment, might modify CAG. Adult male rats untreated, estradiol benzoate treated (EB) $300 \mu \mathrm{g} / \mathrm{kg}$ or vehicle treated (VE) for 3 days, were Sham or left adrenalectomized after 18 to 20 min procedure (prolonged surgery) or after 14 to 16 min procedure (short surgery). The response to surgical stress was evaluated by comparison of the left adrenals between Sham and left adrenalectomized animals matched for treatment, surgery and body weight. Autopsy was done 88-90h after surgery. The right adrenals following prolonged surgery for unilateral adrenalectomy after EB or VE treatment were examined histologically. The number of rats with enlarged zona glomerulosa was greater $(p<0.01)$ in $\mathbf{E B}$ than in VE-treated rats. Prolonged surgery induced significant stress response in untreated and EB-treated rats in parallel with attenuation of CAG. Stress response of lower magnitude in VE (22\%) than in EB-treated rats (61.4\%) was followed by significant CAG. After short duration surgery, significant CAG, with an absence of stress response, was apparent in VE and EB rats. The extent of CAG was found inversely related to initial adrenal size. In conclusion, these results suggest that prolonged surgical stress, increased response to this stress and enlarged glomerulosa are negatively related to CAG, possibly through CAG suppression by increased ACTH and/or adrenocortical secretion.
\end{abstract}

Key words: compensatory adrenal growth, estradiol, surgical stress

\section{INTRODUCTION}

Until $1974^{1,2}$, compensatory adrenal growth (CAG) after unilateral adrenalectomy was attributed to the

Address correspondence and requests for reprints to: Nicholas Bikas, 209 Alexandras Ave., GR-115 23

Athens-Greece, Tel. 01-6469500, Fax 01-6454988, e-mail:maria3nb@OTEnet.gr

Received 14-12-01, Revised 07-02-02, Accepted 10-04-02
glucocorticoid-ACTH negative feedback system. Later a number of studies demonstrated that ACTH is not required for $\mathrm{CAG}^{3,4}$, that the early proliferative response triggered by unilateral adrenalectomy is neurally mediated ${ }^{5-7}$, and that CAG is inhibited by sympathectomy $^{8}$. Furthermore, it was found that injection of ACTH at the time of left adrenalectomy inhibited the usually observed increase in $\left[{ }^{3} \mathrm{H}\right]$ thymidine incorporation into the right adrenal DNA at 12 or $18 \mathrm{~h}$ but 
increased the RNA content and prevented the increase in adrenal DNA content at 24h. In Sham operated (Sham) rats, ACTH caused a dose-dependent increase in adrenal weight, in the RNA to DNA ratio at $24 \mathrm{~h}$, and in adrenal DNA at $72 \mathrm{~h}^{9}$. Grizzle and Dunlap ${ }^{4}$ found that aldosterone after intraperitoneal administration blocks CAG. Philips et a ${ }^{10}$ found no effect on CAG after subcutaneous administration of aldosterone, in contrast to dexamethasone administration which was followed by attenuation of CAG.

Other studies showed that a cleavage product of the N-terminal glucopeptide $\mathrm{N}-\mathrm{POMC}^{1-76}$ may be the non-ACTH derived adrenal mitogen ${ }^{11}$. It was suggested that this mitogenic peptide N-POMC (1-48/9) was generated post-secretionally by a neurally mediated cleavage of N-POMC ${ }^{1-76}$ at the adrenal gland thus initiating $\mathrm{CAG}^{12}$. It was also found that the insulin-like growth factors (IGF1 and 2) were increased in extracts of adrenal glands $24 \mathrm{~h}$ following unilateral adrenalectomy, whereas at the $68 \mathrm{~h}$ the increase remained significant only for IGF $1^{13}$.

In three later studies, another growth factor was incriminated as mediator of the proliferation in the CAG response, namely the basic fibroblast growth factor (bFGF) ${ }^{14-16}$. Interestingly, an earlier study ${ }^{17}$ had demonstrated that in monolayer cultures of bovine adrenocortical cells, angiotensin II as well as bFGF stimulated cell proliferation and $\left[{ }^{3} \mathrm{H}\right]$ thymidine incorporation into DNA and their stimulatory effect was blocked by ACTH.

The antagonism of ACTH to the two growth factors and the finding that $\mathrm{ACTH}$ administration at the time of unilateral adrenalectomy prevented the growth normally seen in the remaining gland $24 \mathrm{~h}$ after surgery $^{9}$ stimulated our interest to examine the role of surgical stress on CAG. Furthermore, since it has been demonstrated that estradiol augments pituitary ACTH secretion in male rats ${ }^{18}$ and in order to enhance the ACTH response to stress, we also examined CAG after estradiol administered for three consecutive days before Sham or unilateral adrenalectomy.

We considered that an experimental study examining the effect of surgical stress on the growth of the remaining adrenal after unilateral adrenalectomy might prove useful in view of the high frequency of adrenal incidentalomas in humans ${ }^{19}$ and the need for unilateral adrenalectomy in about $38 \%$ of patients with such masses ${ }^{20}$. With this possible implication in mind and because of the scarcity of pertinent information in adult rats as compared to juvenile or immature $\operatorname{rats}^{3-7,9,10,12,21}$, we elected to perform our experiments in adult male rats.

\section{MATERIALS AND METHODS}

\section{Animals}

Male Wistar rats raised in our laboratory were studied at the adult age of 106-122 days under automatically controled light cycle (light on from 7.00 to $21.00 \mathrm{hr}$ ) and unrestricted rat chow and water supply. Estradiol benzoate (EB) fresh solution in olive oil (oil sterilized at $120^{\circ} \mathrm{C}$ for 1 hour) was used (s.c.) at the pharmacological dose of $300 \mu \mathrm{g} / \mathrm{kg}$ body weight daily for three consecutive days. Controls were treated with the vehicle (VE), sterilized olive oil (s.c.) $1 \mathrm{ml} / \mathrm{kg}$ body weight. On the day following the last injection, in half of the rats with similar treatment, the left adrenal was removed under ether anaesthesia and in the other half Sham adrenalectomy was performed. One group of untreated adult rats was also studied after Sham or unilateral adrenalectomy. One group of untreated rats of similar age and weight was used as control to this group.

The left adrenal gland immediately after removal was trimmed of surrounding fat and tissues and was weighed immediately to the nearest $0.01 \mathrm{mg}$. To prevent possible dehydration, cleaning of the gland was performed on filter paper saturated in $0.9 \% \mathrm{NaCl}$ solution. The rats were autopsied 88-90 hours after surgery and each adrenal gland was weighed. Seminal vesicles, thymus and testes were also weighed after removal and trimmed of surrounding tissues. Four intact rats with a body weight and age representative of the groups studied were sacrificed on the day following the last injection of EB for measurement of serum estradiol by RIA as described ${ }^{22}$.

\section{Surgical stress}

Surgery: The anaesthesized rat was removed after 1.5-2.5 min from a ventilated plexiglas chamber filled with ether vapor. During surgery, when needed, ether was administered again on the surgical table or the rat was placed again in the plexiglas chamber.

The surgical procedure, alternatively left or Sham adrenalectomy, was performed via a left dorsal later- 
al incision. This procedure lasted from 14 to $16 \mathrm{~min}$ in VE or EB-treated rats with low body weight. In VE or EB-treated rats with high body weight, because of time needed for suturing the larger skin and retroperitoneal incisions, the procedure lasted from 18 to 20 min. In untreated adult rats despite lower body weight, the duration of the surgical procedure and ether inhalation were kept from 18 to 20 min purposely so as to be similar to the duration in adult rats with high body weight.

Care was taken that duration of the surgical procedure and ether inhalation be similar during left and Sham adrenalectomy between similarly treated rats of the same age and weight.

\section{Histologic examination}

Histologic examination of the right adrenals was done in 35 left Adx and 8 Sham Adx rats. All these rats were submitted to the 18 to 20 min surgical procedure. In 21 out of the 35 left Adx rats the surgical procedure took place on the day following EB treatment, $300 \mu \mathrm{g} / \mathrm{kg}$ body weight for three consecutive days, and in the remaining 14 rats following VE treatment.

Each adrenal, after being weighed, was fixed in Bouin's solution embedded in paraffin and serially sectioned at 5-6 $\mu \mathrm{m}$. Sections were stained in hematoxylin-eosin.

\section{Measures of the response to surgical stress and of the compensatory adrenal growth}

For the evaluation of the response to surgical stress of different duration after EB or VE treatment, we compared the mean weight of left adrenals in Sham with the mean weight of left adrenals removed in $\mathrm{Adx}$ rats under operation of the same duration and after the same treatment. One group of 6 untreated, unstressed adult rats of similar age and weight to untreated surgically stressed rats by the long duration 18-20 min Sham or left adrenactomy, was also studied for the evaluation of the stress response by comparison of the left adrenals among these three groups of rats.

The analysis for compensatory adrenal growth was done by two methods: 1) Comparison of the absolute raw weights of the right adrenals between Sham and similarly treated left adrenalectomized rats; 2) Comparison of the normalized right adrenal with left ad- renal, between Sham and left adrenalectomized rats. Comparison of the relative weights $(\mathrm{mg} / 100 \mathrm{~g}$ body weight) of right adrenals between Sham and Adx rats gave less reliable results than the other two methods, which is in accordance with the results of Grizzle and Dunlap $^{4}$ and Philips et $\mathrm{al}^{10}$. For this reason this method was not included.

The normalization of the right adrenal by left adrenal was initiated by Grizzle and Dunlap ${ }^{4}$ and used by Philips et al. ${ }^{10}$ after modification. We preferred this modification because the $\mathrm{Q}$ factor, after adaptation to the design of our study, represents the stress response as evaluated in our study. Accordingly, for correction of the left adrenal, which was removed at adrenalectomy and was therefore uninfluenced by the stress of the surgical procedure to which the remaining adrenal was exposed, each left adrenal was multiplied by factor $\mathrm{Q}$ which was estimated as follows:

$\mathrm{Q}=\frac{\text { Mean weight of left adrenals from Sham-operated rats }}{\text { Mean weight of the excised left adrenals from left Adx rats }}$ matched for age, weight, treatment and surgical stress.

The normalized right adrenal in Adx rats is given by the ratio right adrenal/corresponding left adrenal corrected for the surgical stress to which the remaining right adrenal was exposed. This ratio represents the difference in weight of the remaining from the removed adrenal mostly due to the neurally mediated adrenal hyperplasia, since hypertrophy due to stress is eliminated after dividing the remaining adrenal by the removed adrenal corrected for stress.

For normalization of the right adrenal in Sham Adx rats, we used the ratio: Right adrenal Sham/left adrenal Sham, of the corresponding age, weight, treatment and surgical stress.

\section{Statistics}

Statistical analysis was done by the Student's unpaired t-test, $\mathrm{X}^{2}$ test and one way ANOVA followed by the Sheffe test ${ }^{23}$. Logarithmic transformations were used for the Student's t-test when needed.

\section{RESULTS}

The concentration of serum estradiol on the day following the $3^{\text {rd }}$ injection of estradiol benzoate in four intact rats was $1441.2 \pm 24.6 \mathrm{pg} / \mathrm{ml}$. This concentration was extremely high compared to the levels of $40.0 \pm 3.6$ 
$\mathrm{pg} / \mathrm{ml}$ found in eight untreated rats.

Estradiol treatment decreased seminal vesicle weight by $60 \%$, testicular weight by $13 \%$ and thymus weight by $25 \%$ conversely to an increase of adrenal weight of $31.8 \%$ (Table 1 ).

The results on the effect of estradiol in Adx rats were similar to those in table 1 as far as the decrease in seminal vesicle weight, which was of the order of $61 \%$. On the other hand, there was a $28.76 \%$ increase in the right adrenal weight following EB treatment, (right adrenal weight $38.5 \pm 1.2 \mathrm{mg}$ versus $29.9 \pm 1.0$ $\mathrm{mg}$ in vehicle treated animals, $\mathrm{p}<0.0005$ ).

The histologic examination of right adrenals in 21 rats, after unilateral adrenalectomy preceded by EB treatment, showed increased thickness of the glomerulosa (Figure 1) in 18. In 14 Adx rats, after VE treatment only 4 showed hypertrophy of the glomerulosa. The number of rats with enlarged glomerulosa was significantly greater (by $\mathrm{x}^{2}$ test, $\mathrm{p}<0.01$ ) in EB-treated than in VE-treated rats. In six Sham rats treated with EB, hypertrophy of glomerulosa was also present (but to a lesser extent) at $0.057 \mathrm{~mm}$, compared to 0.076-0.095 mm found after unilateral adrenalectomy in 18 out of the 21 EB-treated animals. In 10 out of 14 VE-treated rats, the thickness of the glomerulosa ranged from $0.038-0.047 \mathrm{~mm}$.

Evaluation of the stress response to the long surgical procedure in untreated rats (18-20 $\mathrm{min}$ ) by comparison of left adrenals among untreated Sham, left Adx and unoperated controls, revealed a significant difference $\mathrm{F}=5.92(\mathrm{p}<0.05)$, indicating a significant stress response. The weight of left adrenals from Sham

Table 1. Organ weights after estradiol benzoate or vehicle treatment for three consecutive days prior to surgery in Sham adrenalectomized adult rats.

\begin{tabular}{lll}
\hline Adult rats (106-122 days) & Vehicle $^{14}$ & Estradiol $^{14}$ \\
\hline Body weight $(\mathrm{gr})$ at sacrifice & $282.4 \pm 16.9$ & $281.6 \pm 12.2$ \\
Adrenal weight $(\mathrm{mg})$ & $50.8 \pm 2.0$ & $67.0 \pm 2.6^{*}$ \\
Seminal vesicle weight $(\mathrm{mg})$ & $1051.0 \pm 108.8$ & $417.2 \pm 43.1^{\dagger}$ \\
Testicular weight $(\mathrm{mg})$ & $3215.9 \pm 199.6$ & $2979.3 \pm 98.5^{\ddagger}$ \\
Thymus weight $(\mathrm{mg})$ & $235.0 \pm 17.6$ & $176.1 \pm 13.3^{\S}$ \\
\hline
\end{tabular}

Values are means $\underline{ \pm S E}$; Number of rats in parentheses.

" $\mathrm{p}<0.0005$ vs vehicle

$\dagger \mathrm{p}<0.005$ vs vehicle after logarithmic conversion of values

$\ddagger \mathrm{p}<0.02$ vs vehicle

$\S \mathrm{p}<0.01$ vs vehicle rats was found increased $(\mathrm{p}<0.01)$ compared to unoperated controls, and higher compared to left adrenals of left Adx rats $(p=0.05)$, by Sheffe test.

The relation between the response to the stress of surgery and the CAG demonstrated in Figure 2 shows that in EB-treated and untreated rats the significant stress response is paralleled by suppression of the CAG. Conversely, in VE-treated rats, with a significant stress response of $22.2 \%$, versus $61.4 \%$ in EBtreated littermates, CAG was found to be significant. After a shorter surgical procedure (Figure 3) there was a nonsignificant stress response in VE and EBtreated rats, whereas CAG was significant (Figure 3). The differences in body weight between the rats exposed to surgery of different duration were highly significant. There was no difference in body weight among rats exposed to surgery of similar duration (Table 2). In rats exposed to prolonged surgery, the thymus weight of $206.3 \pm 19.6 \mathrm{mg}$ in Adx rats after EB was found lower $(\mathrm{p}<0.05)$ when compared to thymus weight of $287.8 \pm 26.6 \mathrm{mg}$ after $\mathrm{VE}$ administration.

In Figures 2 and 3 regarding the right to left adrenal weight ratio, one sees that right Sham/left Sham ratio was less than 1 in all experiments. In the 20 adult Sham rats, $70 \%$ had a larger left adrenal gland and $30 \%$ had a right adrenal larger than the left. According to measurements in 18 unoperated and untreated adult rats of similar age, evaluation by the $\mathrm{x}^{2}$-test did

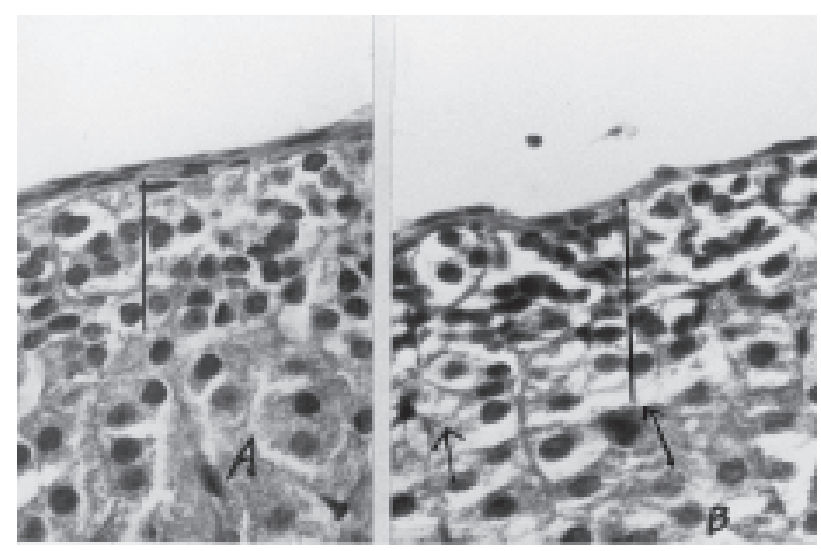

Figure 1. Histologic sections of right adrenals in adult male rats with left adrenalectomy carried out in 18 to $20 \mathrm{~min}$, after treatment with estradiol benzoate (B) or its vehicle (A); hematoxylin-eosin $\mathrm{x} 400$. Note increased thickness of glomerulosa after estradiol treatment, compared to vehicle treatment. Obvious lipid accumulation in the cytoplasm of the cells of the zona glumerulosa in Figure B. 
not show a significant difference in the distribution observed between Sham and control rats. The right to left adrenal gland ratio $0.929 \pm 0.021$ in 18 unoperated and untreated controls was not significantly different from the ratio $0.946 \pm 0.022$ in Sham rats.

To find the relation between the initial adrenal size and the extent of CAG as expressed by the right to corrected left adrenal ratio, we combined the two groups of adult rats with different body weight, both in VE or EB-treated, into one in order to correct for

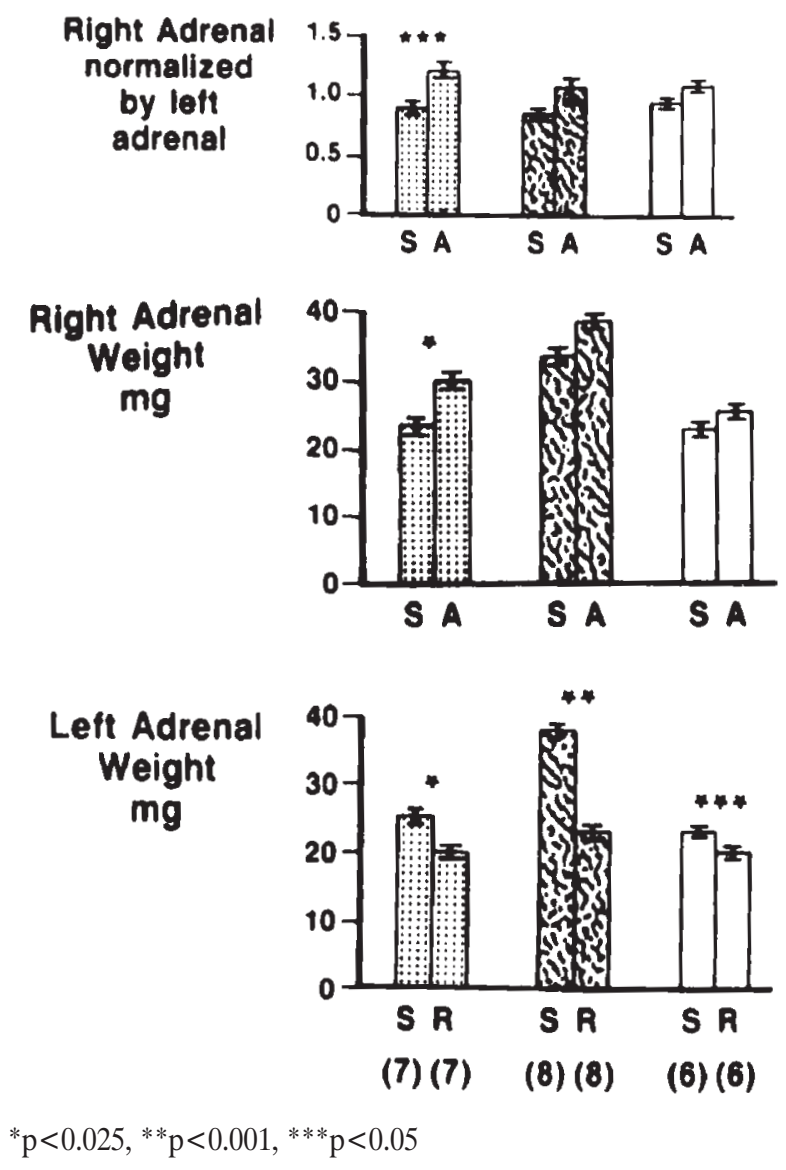

Figure 2. Effect of the response to surgical stress on compensatory adrenal growth (CAG). The response to stress (lower panel) expressed by the difference of adrenal weight in sham operated (Sham) rats (S), when compared to left adrenal removed (R) after similar treatment, at unilateral adrenalectomy of similar duration (18-20 min). CAG (middle panel) evaluated by comparison of the right adrenal weight between Sham (S) and left adrenalectomized (A) rats. CAG (upper panel) evaluated by comparison of the right/left adrenal weight ratio in Sham $(\mathrm{S})$ to the right/corrected left adrenal weight ratio (see methods) in left Adx rats (A). Dotted columns vehicle treated, striped columns estradiol benzoate treated, open columns untreated rats. Data are means $\underline{+} \mathrm{SE}$ for each group. Number of rats in parentheses. the left adrenals, using one factor $\mathrm{Q}$ for similarly treated rats. Thus, the correction of the left adrenals corresponded to the increase due to the surgical stress, which was of the order of $18.9 \%(\mathrm{P}<0.01)$ in vehicle and $38.3 \%(\mathrm{P}<0.001)$ in EB-treated animals.

The results of Figure 4 show a significant difference in the extent of CAG between groups with different
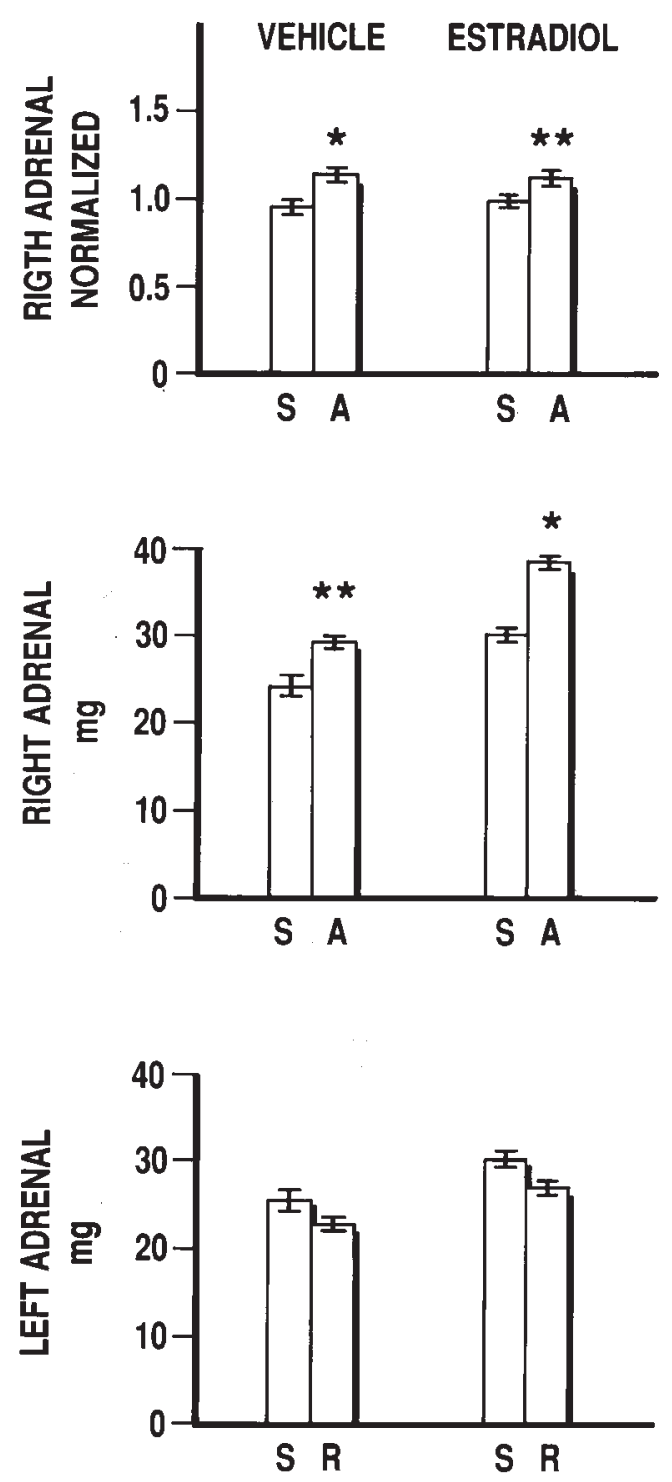

${ }^{*} \mathrm{P}<0.005,{ }^{* *} \mathrm{P}<0.02$

Figure 3. Lack of stress response (lower panel) paralleled by compensatory adrenal growth (two upper panels) in adult male rats vehicle or estradiol benzoate treated with duration of surgical procedure at left unilateral adrenalectomy (A) and left Sham operation (S) 14-16 min. Note lack of significant left adrenal enlargement after Sham operation (S) versus left adrenal removed $(\mathrm{R})$ at surgery (lower panel). Data are means \pm SE for each group ( $n=6$ or $7 /$ group). 
Table 2. Differences in body weight between rats exposed to prolonged and short surgery

\begin{tabular}{lll}
\hline & Prolonged surgery & Short surgery \\
\hline & \multicolumn{2}{c}{ Vehicle treated } \\
\cline { 2 - 3 } Sham adrenalectomized & (7) $324 \pm 12$ & (7) $241 \pm 11^{*}$ \\
Left adrenalectomized & (7) $335 \pm 13$ & (7) $243 \pm 7^{\dagger}$ \\
& \multicolumn{2}{c}{ Estradiol benzoate treated } \\
\cline { 2 - 3 } Sham adrenalectomized & (8) $308 \pm 11$ & (6) $244 \pm 8^{\ddagger}$ \\
Left adrenalectomized & (8) $312 \pm 11$ & (6) $244 \pm 10^{\ddagger}$ \\
\hline
\end{tabular}

Body weight in gr means $+\mathrm{SE}$; number of rats in parentheses.

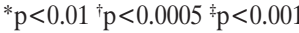
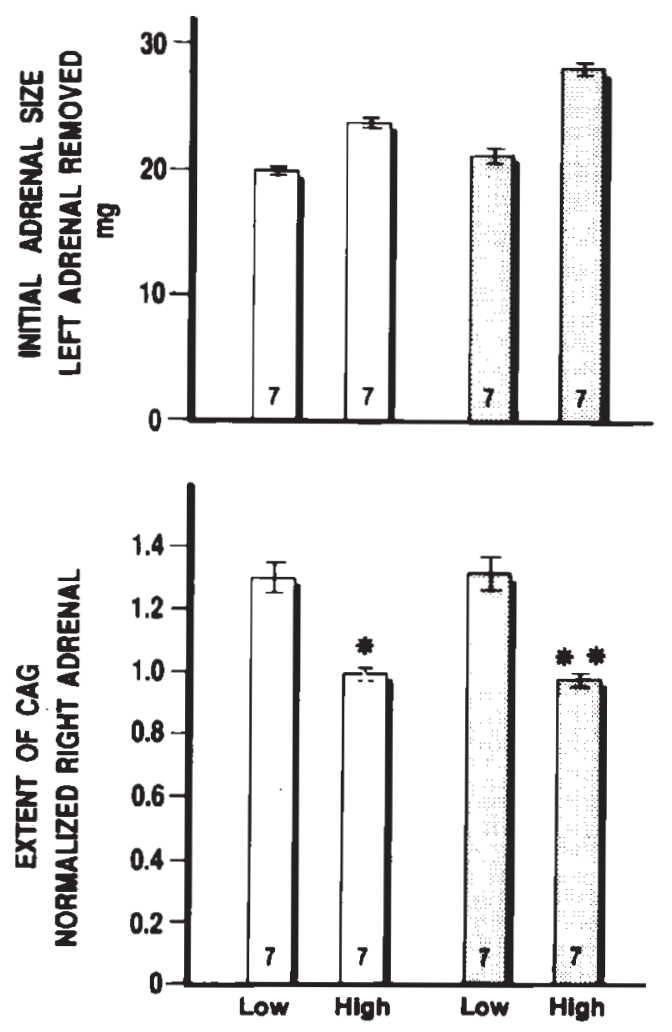

\section{Subgroups of low and high initlal adrenal size}

${ }^{*} \mathrm{P}<0.025,{ }^{*} \mathrm{P}<0.01$ versus normalized right adrenals under similar treatment.

Figure 4. Inverse relationship of the size of removed adrenal, at left unilateral adrenalectomy (upper panel) to the extent of compensatory adrenal growth, expressed by right adrenals normalized by corrected left adrenals after similar treatment (lower panel), vehicle: open columns, estradiol treated rats: shaded columns. Each group of similar treatment was separated into two subgroups of low and high initial adrenal size respectively, according to the weight of removed adrenal found in each rat, and the corresponding normalized right adrenals in each subgroup. Data are means \pm SE for each group. Number of rats at the bottom of each column. initial adrenal size, namely decreased CAG in rats with higher initial adrenal size, both in vehicle and EBtreated rats.

\section{DISCUSSION}

According to the results of this study, a long duration surgical procedure, such as Sham adrenalectomy or unilateral adrenalectomy under ether anaesthesia, was followed by a significant adrenotrophic effect. In contrast, there was no significant adrenal enlargement in Sham rats submitted to a surgical procedure of short duration. Since CAG is evaluated by comparison between the right/corrected, left adrenal ratio in left Adx and the right/left adrenal ratio in Sham rats, our results showed that for an accurate evaluation of CAG in the adult rat, the surgical procedure should be of the same duration in Sham and Adx animals.

On the other hand, stress of similarly long duration in VE and EB-treated animals resulted in higher adrenotrophic response after EB treatment than after VE treatment and in nonsignificant $C A G$ after $\mathrm{EB}$ treatment.

A decrease in testosterone after EB on the day of surgery (results not included), shown by the decrease in seminal vesicle weight ${ }^{24,25}$, would result in the elimination of the androgen suppressive effect on ACTH secretion and glucocorticoid clearance ${ }^{26}$. This, in association with estradiol-induced shortening of corticosterone plasma half-life ${ }^{18}$, might increase the ACTH response to stress through decreased negative feedback ${ }^{27}$ and explain the difference found between EB and vehicle treated rats after stress of a similarly long duration. The increase in adrenal weight after estradiol treatment, found in the present study and the resulting thymolytic effect ${ }^{28}$, are in accordance with the increase in adrenal weight found in adult male rats and the increase in corticosterone after ether stress $^{26}$.

Our results also show that surgery for unilateral adrenalectomy of long duration in untreated rats was followed by suppression of CAG in parallel with a significant stress response. Conversely, a short duration unilateral adrenalectomy resulted in significant CAG in vehicle and estradiol treated rats, with a body weight similar to that of untreated rats with suppressed CAG.

The overall results suggest that increased release of endogenous ACTH, due to prolonged stress at sur- 
gery and/or increased response to this stress, may have an adverse effect on CAG. These data support previous findings ${ }^{9}$, which have shown inhibition of CAG after pharmacological manipulation with ACTH.

Histologic sections of the right adrenals examined after prolonged surgery showed increased thickness of the zona glomerulosa present in a significantly higher number in EB compared to VE-treated rats. The $\mathrm{EB}$ induced higher $\mathrm{ACTH}$ release in response to the surgical stress compared to VE, suggested by the $61.4 \%$ in $\mathrm{EB}$ versus the $22 \%$ stress response in VEtreated rats, might be one of the reasons for this differentiation, since ACTH treatment in adult female rats for one or three days had been found to activate gene transcription of basic fibroblast growth factor (bFGF) in the zona glomerulosa ${ }^{29}$. It was also shown that exogenous bFGF stimulated cell proliferation in capsule-glomerulosa preparations in vitro ${ }^{14}$ and that in the presence of estradiol but not in its absence bFGF stimulated cell growth in cultured rat anterior pituitary cell line ${ }^{30}$.

On the other hand, partial enlargement of glomerulosa in EB treated Adx rats might be present at the time of surgery since EB and the daily stress of its administration preceded surgery for three consecutive days. An increased secretion of aldosterone from the already enlarged glomerulosa, in response to high ACTH released by surgical stress ${ }^{31}$, might contribute to the suppression of CAG in the goup of EB rats with prolonged surgery, according to previous findings $^{4}$. This possibility is corroborated by the results of another study ${ }^{32}$ showing activation of the renin angiotensin system on the third day after daily administration of ethinyl estradiol s.c. to adult male rats, in a dosage quite similar to that used in the present study.

Aldosterone synthase was recently detected in the rat hippocampus ${ }^{33}$. A central effect of aldosterone after binding to hippocampal mineralocorticoid receptors might result in inhibition of the hypothalamo-pituitary-adrenal system, an effect antagonized by estradiol through suppression of these receptors ${ }^{34}$. Accordingly, an inhibitory effect of aldosterone after EB on the neurally mediated adrenal hyperplasia should be expected locally on the remaining adrenal and not at the central level. Another study ${ }^{35}$ favours the interpretation of aldosterone involvement in attenuation of CAG by demonstrating inhibition of CAG by isoproterenol, which was shown to stimulate steroido- genesis in perifused capsule-glomerulosa preparation, causing greater increase in secretion of aldosterone than corticosterone.

We should also consider the possibility of attenuation of CAG by increased corticosterone ${ }^{10}$ in the group submitted to a longer duration of stress after EB treatment through a synergistic effect of ACTH and interleukin- 6 on corticosterone release ${ }^{36}$. In favour of this assumption are the production of interleukin- 6 by the zona glomerulosa ${ }^{37}$ and its increase by $\mathrm{ACTH}^{38}$ when combined with three of our findings (the enlarged zona glomerulosa, the higher response to prolonged surgical stress after EB, and the lower thymus weight compared to VE treatment) suggesting higher ACTH release and corticosterone, respectively ${ }^{28}$.

As concerns the inverse relation between initial adrenal size and the extent of CAG, our results in adult rats confirm the results of Philips et $\mathrm{al}^{10}$. It is possible that the interaction between initial adrenal size and CAG in adult rats was facilitated by stress, which would increase endogenous glucocorticoids and aldosterone to a greater extent in the presence of larger adrenals.

On the other hand, if we accept that a neurally mediated proteolytic cleavage of a circulating inactive mitogenic precursor (N-POMC-1-76-) is one mechanism for control of $\mathrm{CAG}^{12}$, and consider the present evidence of intra-adrenal release of $\mathrm{CRH}$ and $\mathrm{ACTH}^{39}$, we may postulate that N-POMC (1-76) released by the adrenal at the time of surgery is not cleaved to the mitogenic peptide N-POMC (1-48/9) because substances released by stress locally by the remaining adrenal may inhibit this proteolytic cleavage and ultimately CAG.

Our finding is that a short duration surgery for unilateral adrenalectomy followed by significant CAG in estradiol treated rats in parallel with no stress response could be attributed to bFGF, a possible mediator of the adrenocortical proliferation in the CAG response ${ }^{14,16}$, and to estradiol-induced increase in bFGF receptors ${ }^{30}$. This assumption is supported by the phenotype of the proliferating cells in the CAG response to unilateral adrenalectomy, which were found between 24 and 96 hrs after unilateral adrenalectomy in the outermost region of the zona fasciculata and not in the glomeru$\operatorname{losa}^{40}$.

In conclusion, the overall results of the present study suggest that in adult male rats, prolonged surgi- 
cal stress, enhanced response to this stress and high initial adrenal size have a suppressive effect on CAG, apparently through increased ACTH and/or adrenocortical secretion. Furthermore our findings may have implications for research concerning CAG in adult rats as they show the importance of keeping equal timing in surgical procedures at Sham and at unilateral adrenalectomy in order to avoid an artifact due to unequal duration of surgery.

\section{REFERENCES}

1. Ganong NF 1970 Control of adrenocorticotropin and melanocyte sti-mu-lating hormone secretion. In: Martin L, Motte M, Fraschini F (eds) The Hypothalamus, New York: Academic Press; pp, 313-314.

2. Yates FE, Marsh DJ, Maran JW 1974 The adrenal cortex. In : Mount-castle NI (ed) Medical Physiology, St.Louis: Mosby Co; pp, 1710.

3. Engeland WC, Shinsako J, Dallman MF, 1975 Corticosteroids and $\mathrm{ACTH}$ are not required for compensatory adrenal growth. Am J Phy-siol 229: 1461-1464.

4. Grizzle WF, Dunlap NE, 1984 Aldosterone blocks adrenal compen-sa-to-ry hypertrophy in the rat. Am J Physiol 246 (En-docrinol Metab 9): E306-E310.

5. Engeland WC, Dallman MF, 1975 Compensatory adrenal growth is neurally mediated. Neuroendocrinology 19 : 352-362.

6. Dallman MF, Engeland WC, Shinsako J, 1976 Compensatory adre-nal growth: a neurally mediated reflex. Am J Physiol 231: 408-414.

7. Engeland WC, Dallman MF, 1976 Neural mediation of compensato-ry adre-nal growth. Endocrinology 99: 16591662.

8. Kleitman N, Holzwarth MA, 1985 Compensatory adrenal cortical growth is inhibited by sympathectomy. Am J Physio-1 248: 261-263.

9. Dallman MF, Engeland WC, Holzwarth MA, Scholz PM, 1980 Adre-no-cor-ti-co-tropin inhibits compensatory adrenal growth after unilateral adre-na-lectomy. Endocrinology 107: 1397-1404.

10. Philips R, Crock C, Funder J, 1985 Effects of mineralocorticoids and glu-co-corticoids on compensatory adrenal growth in rats. Am J Phy--siol 248 (Endocrinol Metab 11): E450-E456.

11. Estivariz FE, Iturriza FV, McLean C, Hope J, Lowry PJ, 1982 Stimulation of adrenal mitogenesis by N-terminal proopiocortin peptides. Nature 297: 419-422.

12. Lowry PJ, Silas L, Linton EA, McLean C, Estivariz FE, 1983 Pro- $\gamma$-me-lanocyte-stimulating hormone cleavage in adrenal gland under-going compensatory growth. Nature 306: 70-73.

13. Jackson S, Hodgkinson S, Estivariz FE, Lowry PJ, 1991 IGF1 and 2 in two models of adrenal growth. J Steroid Biochem Molec Biol 40: 399-404.

14. Basile DP, Holzwarth MA, 1993 Basic fibroblast growth factor may mediate proliferation in the compensatory adrenal growth response. Am J Physiol 265: 1253-1261.

15. Basile DP, Holzwarth MA, 1994 Basic fibroblast growth factor receptor in the rat adrenal cortex: effects of suramin and unilateral adrenalectomy on receptor numbers. Endocrinology 134: 2482-2489.

16. Holzwarth MA, 1995 Evidence for fibroblast growth factor mediation of compensatory adrenocortical proliferation. Endocr Res 21: 115-119.

17. Gill GN, Ill CR, Simonian MH, 1977 Angiotensin stimulation of bovine adrenocortical cell growth. Proc Natl Acad Sci USA 74: 5569-5573.

18. Kitay JI, 1962 Effects of estradiol on pituitary-adrenal function in male and female rats. Endocrinology 72: 947954.

19. Aron DC, 1997 Non-functioning adrenal tumors: An epidemiological per-spective. International Conference on the Management of "Non-Fun-ctioning" Adrenal Tumors, Vouliagmeni, Greece, Abstract Book; pp, 8-15.

20. Terzolo M, Ali A, Osella G, Angeli A, 1997 Adrenal incidentaloma (1): Epidemiological and clinical data from the National Italian Study Group. International Conference on the Management of "Non-Fun-ctioning" Adrenal Tumors, Vouliagmeni, Greece, Abstract Book p, 67.

21. Holzwarth MA, Wilkinson CW, Dallman MF, 1980 Compensatory ad-renal growth in immature and mature male rats. Neuroendo-cri-no-lo-gy 31: 34-38.

22. Sfikakis A, Spyraki C, Sitaras N, Varonos D, 1978 Implication of the est-rous cycle on conditioned avoidance behavior in the rat. Physiol Behav 21: 441-446.

23. Downie NM, Heath RW 1974 An introduction to the analysis of va-ri-ance. In : Har-per Interna-tio-nal Edition (eds) Basic Statistical Methods, edn 4, New York: Evanston, San Francisco, London: Harper and Row Pu-blishers; pp, 206-223.

24. Zarrow MX, Yochim JM, McCarthy JL 1964 The androgens. In: Ex-peri-mental Endocrinology. New York and London: Acade-mic Press; pp, 125-150.

25. Mooradian AD, Morley JE, Korenman S, 1987 Biological actions of andro-gens. Endocr Rev 8: 1-28.

26. Kitay JI, 1963 Pituitary adrenal function in the rat after gonadecto-my and gonadal hormone replacement. Endocrinology 73: 253-260.

27. Keller-Wood ME, Dallman MF, 1984 Corticosteroid inhibition of ACTH se-cretion. Endocr Rev 5: 1-24.

28. Khalid BAK, Lim ATW, Funder JW, 1983 Steroid effects on protein syn-thesis: mineralocorticoids and glucocorticoids, thymus and pitui-tary. Int Congr Ser 598 : 289-294.

29. Ho MM, Vinson GP, 1995 Endocrine control of the distribution of basic fibroblast growth factor, insulin-like growth factor-1 and transforming growth factor-B1 mRNAs in adult rat adrenals using non-radioactive in situ hybridization. J Endocr 144: 379-387.

30. Takahashi H, Nakagawa S, 1997 Effects of estrogen on cell growth and fibroblast growth factor receptor induction in MtT/Se cells. Endocr Res 23: 95-104.

31. Dallman MF, Akana SF, Cascia CS, Darlington DN, Jacobson L, Le-vin N, 1987 Regulation of ACTH secre- 
tion: variations on a theme of B. Re-c Progr Horm Res 43: 113-173.

32. Menard J, Catt KJ, 1973 Effects of estrogen treatment on plasma renin parameters in the rat. Endocrinology 92: 1382-1387.

33. MacKenzie SM, Clark CJ, Fraser R, Gomez-Sanchez CE, Connel JM, Davis E, 2000 Expression of 11 beta-hydroxylase and aldosterone synthase genes in the rat brain. $\mathrm{J}$ Mol Endocrinol 24: 321-328.

34. De Kloet RE, Vreugdenhil E, Oitzl MS, Jolls M, 1998 Brain corticosteroid receptor balance in health and disease. Endocr Rev 19: 269-301.

35. Holzwarth MA, Cunningham LA, Kleitman N, 1987 The role of adrenal nerves in the regulation of adrenocortical functions. Ann N York Acad Sci 512: 449-464.

36. Salas MA, Evans SW, Levell MJ, Whicher JT, 1990 Inter- leukin-6 and ACTH act synergistically to stimulate the release of corticosterone from adrenal gland cells. Clin Exp Immunol 79: 470-473.

37. Judd AM, Spangelo BL, MacLeod RM, 1990 Rat adrenal zona glomerulosa cells produce interleukin-6. Prog Neuroendocrin Immunology 3: 282-292.

38. Judd AM, McLeod RM, 1992 Adrenocorticotropin increases inter-leukin-6 release from rat adrenal zona glomerulosa cells. Endocrinolo-gy 130: 1245-1254.

39. Ehrhart-Bornstein M, Hinson JP, Bornstein SR, Scherbaum WA, Vinson GP, 1998 Intraadrenal interaction in the regulation of adrenocortical steroidogenesis. Endocr Rev 19: 101-143.

40. Holzwarth MA, Gomez-Sanchez CE, Engeland WC, 1996 Phenotype of proliferating cells stimulated during compensatory adrenal growth. Endocr Res 22: 401-406. 